\title{
Discrete Event Simulation Application in Distribution of Refugees
}

\author{
Huangjing Zhang \\ School of Energy \& Power Engineering, North China Electric Power University, Baoding 071000, \\ China.
}

784314165@qq.com

\begin{abstract}
Nowadays, the refugee crisis has become a worldwide problem. This paper aims to predict refugee crises, design optimal routes and simulate the movement of refugees. Finally, a policy recommendation is proposed, totally based on my research, to those concerned. Firstly, refugee acceptance index is proposed in this paper to predict the refugee population in European countries. Factors, like the safety of six travel routes, a specific country's GDP, and population density, are integrated in the evaluation system. With Fuzzy Analytic Hierarchy Process applied to my model, each country's refugee acceptance index can be exactly calculated and thus assessed. In order to analyze the flow of refugees, I propose a discrete event simulation model. To begin with, a migration route network including 35 cities of 29 European cities is set up. Then, the shortest path between cities can be calculated according to Floyd algorithm. Last, main rules are applied to predict the refugee population of being accepted or deported by each city. To simulate better the dynamic characteristics of refugee crisis, noise interference is used to simulate unstable factors in real situation, which is a random number. Compared with the traditional distribution results, now a proper number of refugees can gather at an ideal city. What's more, the final number of refugees at each city is more homogeneous. So, I suggest that an ideal city should be given priority to offer more rescue; besides, non-governmental organizations are supposed to raise more traffic supplies and guide refugees to choose the optimal path. In order to solve this problem, some specific solutions are proposed, such as increasing refugees allowance to improve the acceptance rate of refugees, adding new cities to the network according to principle of proximity and refugee acceptance index, etc. For example, it is suggested that Sweden and Russia should be given priority. The proposed models are very flexible, which are adapted to predict the flow of refugees under different disturbances and emergencies. Government and non-governmental organizations can use the models to predict the flow of refugees so that they can arrange for the allocation of resources in advance. Meanwhile, refugees can use my model to choose the best possible route to their ideal destination.
\end{abstract}

Keywords: Refugee crisis; discrete event simulation; fuzzy analytic hierarchy process; floyd algorithm.

\section{Introduction}

I decompose the refugee problems into the following steps:

Establish a refugee crisis index evaluation system. Select refugees accepting countries and evaluate the capacity of accepting countries from many aspects. Then evaluate traffic capacity of six routes.

Use them as framework for further analysis.

Use parameters of to simulate the development of the refugee crisis.

Take external disturbance factors which may afect the migration path into considera- tion,change parameters to get simulating results and analyze its effects.

Take emergency into consideration, change the structure of the model to get new results and analyze them again.

\section{General Assumptions}

Models make the following assumptions: 
Refugees are only allow to choose one of the six routes to enter EU, and other approaches are ignored.

There are only two states of refugees, namely, accepted and deported, ignoring the death toll in migration.

\section{Models of Measuring Refugee Crises}

\subsection{Metrics of Refugee Crises.}

The Selection of Parameters

The resources of a country are considered to be the primary factor, which include GDP and per capital GDP, the total population, density of population, growth rate of population, unemployment rate and social security rate.

\subsection{Fuzzy AHP Model.}

To analyze the size of these factors, I use the fuzzy analytic hierarchy process (AHP) to determine each parameter's weight because this method is able to decrease the influence of subjective factors in modeling process.

\section{The Refugees Distribution Simulation Model}

Step 1 Calculating Refugee acceptance index of Each Country

Step 2 Calculating the Probability of Each Route in Six Travel Routes

Step 3 Establishing the Urban Network

Step 4 Simulation

Simulating process

- Process 1: To determine which route should be chosen to enter Europe by generating a random number.

- Process 2: To make decision of stay or departure after arriving at city $i$ in the Figure 2.

Stay Rule:

Generating a random number rand,

If $r a n d \leq$ Dis Ind

Then stay, stay num ${ }_{i}+$, Dis Ind $_{i}=$ Dis Ind $_{i} \quad 0.9998$

End

0.9998 is defined as the descending coefcient.

Departure Rule:

If rand $>$ Dis Ind

Then leave, choose a city nearby with possibility,

TotalDistance $=$ TotalDistance + Distance $_{i j}$

Repeat process 2

- Process 3: Being deported

\section{Result Analysis}

Suppose there are 1,200,000 refugees and calculate new refugee acceptance index of cities. Then I get results as shown in Table 1.

Table 1. new refugee acceptance index of cities

\begin{tabular}{|c|c|c|c|}
\hline $\begin{array}{c}\text { Refugees Being } \\
\text { Accepted }\end{array}$ & $\begin{array}{c}\text { Refugees Being } \\
\text { Deported }\end{array}$ & $\begin{array}{c}\text { Average Travel } \\
\text { Distance/sq.km }\end{array}$ & $\begin{array}{c}\text { Average Number } \\
\text { of City a refugee } \\
\text { need to go }\end{array}$ \\
\hline 528,875 & 671,125 & 12,588 & 35.8 \\
\hline
\end{tabular}




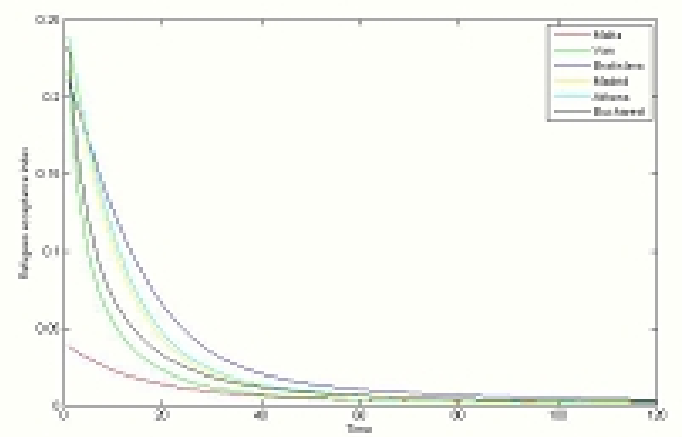

Fig. 1 Refugees acceptance index decreased rapidly at earlier stage

Refugees acceptance index decreased rapidly at earlier stage, while at later period, all of the index are close to zero. That's the reason why most of refugees are deported. More than half of the refugees will be deported. Meanwhile, refugees need to travel 35.8 cities till they are deported, which exceeds the total number of the cities in this network (Fig. 1).

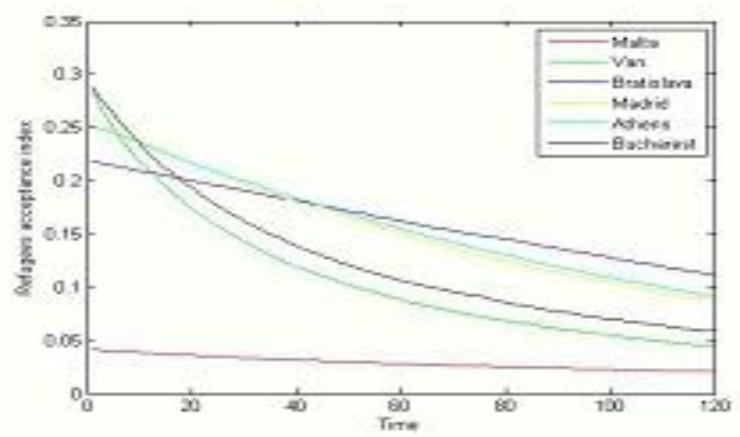

Fig. 2 Refugees acceptance index

Two conclusions are drawn from Fig. 2 shown in the above:

Refugees acceptance index of cities with high refugees acceptance index decline sharply at the beginning, then the variation trend becomes slow.

Refugees are less likely to settle in cities with low refugees acceptance index, so the changing curve is approximately linear.

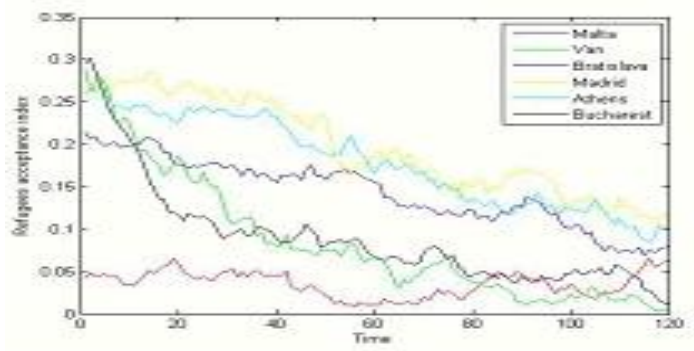

Fig. 3 dynamic impact factor

Obviously, Fig. 3 shown that all the fluctuation degree becomes bigger because of the dynamic impact factor. Especially, Malta, a city with low refugees acceptance index, even exceeds other high index countries in the later period. That is to say, under the circumstances, cities with low acceptance index are more likely to accept more refugees than other high index cities. 


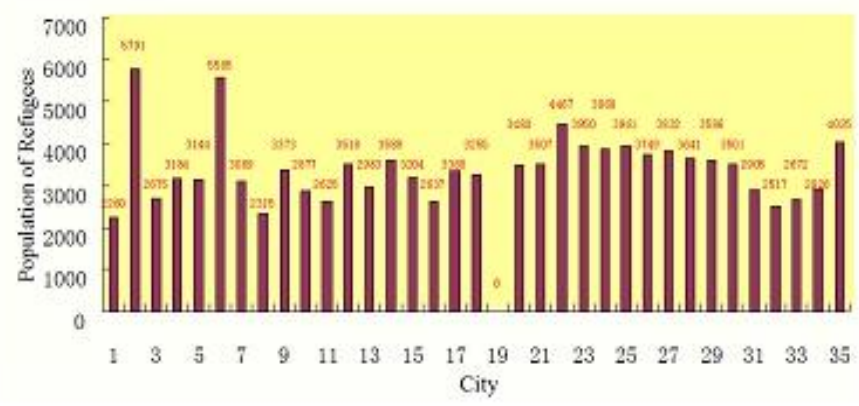

Fig. 4 Refugees have no choice but to detour when meeting an emergency

The nearby cities will be afected too, and the population of refugees in these cities will decrease. The population of refugees being accepted by the entire network will decrease (Fig. 4).

\section{Conclusion}

All the fluctuation degree becomes bigger because of the dynamic impact factor. Especially, Malta, a city with low refugees acceptance index, even exceeds other high index countries in the later period. That is to say, under the circumstances, cities with low acceptance index are more likely to accept more refugees than other high index cities. The nearby cities will be afected too, and the population of refugees in these cities will decrease. The population of refugees being accepted by the entire network will decrease.

\section{References}

[1] Saaty T L. Modeling unstructured decision problems-the theory of analytical hierarchies [J]. Math Comput Simulation ,1978, 20: 147 -158.

[2] Lan Jibin, XU Yang, HUO Liangan, LIU Jiazhong. Research on the Priorities of Fuzzy Analytical Hierarchy Process[J]. Systems Engineering- Theory \& Practice, 2006, 9 : 107-112.

[3] Economic Index. http://zh.tradingeconomics.com/indicators

[4] Economic Index. http://zh.tradingeconomics.com/indicators

[5] Growth Rate of Population. http://www.chinabgao.com/stat/stats/40711.html

[6] Population?Density. https://en.wikipedia.org/wiki/Population_density

[7] Migration Flows-Europe. http://migration.iom.int/europe/

[8] How do migrants get to Europe? http://www.bbc.com/news/world-europe-34131911

[9] Data of Missing Migrants. http://missingmigrants.iom.int/mediterranean 